\title{
Economia agrícola das comunidades romanas do NW peninsular: dados carpológicos da Terronha de Pinhovelo (Bragança, Portugal)
}

\author{
Recibido: 17 Outubro 2007 / Aceptado: 3 Novembro 2007 \\ (C) IBADER- Universidade de Santiago de Compostela 2007
}

Resumo Um estudo paleoetnobotânico realizado sobre macro-restos vegetais do povoado romano da Terronha de Pinhovelo (Nordeste de Portugal), forneceu informações acerca das práticas agrícolas das comunidades indígenas dos séculos IV/V D.C.Foram recolhidos depósitos com quantidades significativas de macro-fosseis vegetais em vários compartimentos e estruturas domésticas. Os dados recolhidos sugerem a existência de uma agricultura cerealífera caracterizada pelo domínio de Triticum spelta, $T$. aestivum, T. compactum e Hordeum vulgare. A fava foi a única leguminosa registada.

Palavras-chave Período romano, NW Península Ibérica, Agricultura.

Abstract A palaeoethnobotanic study over plant macrofossils from the Roman settlement of Terronha de Pinhovelo, in Northeast Portugal as provided evidences from the agriculture of the indigenous communities during the IV/V centuries A.D. Sediments from several compartments and domestic structures were sampled, providing significant amounts of plant macrofossils. The data suggests the prevalence of a cereal agriculture, mainly of spelt, bread wheat, club wheat and hulled barley. The only non-cereal cultivated plant was the horsebean.

Key-words Roman period, NW Iberia, Agriculture.

\section{João Pedro Tereso}

Laboratório de Paleoecologia e Arqueobotânica, IGESPAR CIBIO - Centro de Investigação em Biodiversidade e Recursos Genéticos \& Faculdade de Ciências, Universidade do Porto e-mail: jptereso@gmail.com

\section{Introdução}

O estudo paleobotânico da Terronha de Pinhovelo, desenvolvido pelo signatário no âmbito de uma tese de mestrado, enquadra-se num projecto de investigação a decorrer no Concelho de Macedo de Cavaleiros (Distrito de Bragança) por intermédio da Associação Terras Quentes. Os trabalhos arqueológicos decorreram sob a direcção científica do signatário e de Helena Barranhão, Lúcia Miguel e Carlos Mendes.

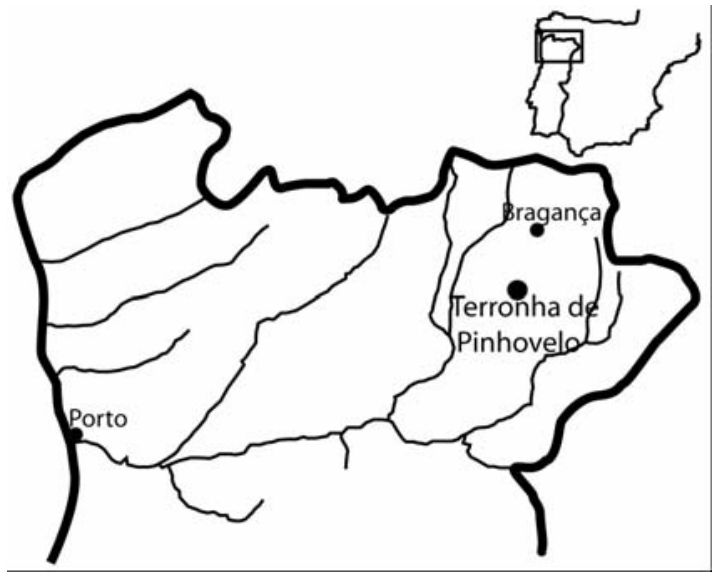

Figura 1.- Localização da Terronha de Pinhovelo

A Terronha de Pinhovelo é um povoado da Idade do Ferro com uma ocupação romana muito marcada, sendo sugerida por alguns materiais arqueológicos cerâmicos uma ocupação contínua entre a Proto-história e o final da presença romana na região (Tereso, 2007; Barranhão e Tereso, 2006). Os macro-restos vegetais analisados neste estudo são provenientes da última grande fase de ocupação da jazida, datável dos séculos IV/V D.C. pela presença de formas e decorações características de Terra Sigillata Hispânica Tardia (Silva, 2007). 
Este povoado inseria-se no território dos Zoelae (Civitas Zoelarum do Conventus Asturum) etnia conhecida de diversas fontes clássicas, das quais se salienta a Naturalis Historia de Plínio-o-Velho. Este autor refere que o linho dos Zoelae era exportado para a Península Itálica onde era utilizado para o fabrico de redes de caça (Guerra, 1995). Embora se deduza, assim, a inserção desta região na ordem económica romana, marcadamente mercantil, é presumível que a presença deste povoado num espaço rural do império, longe dos estímulos comerciais urbanos, colocaria uma particular ênfase na componente agropastoril da sua economia como forma de garantir a sua auto-suficiência (Tereso, 2007).

Como tal, no projecto de escavação e estudo da Terronha de Pinhovelo, desde cedo se percebeu que a realização de um estudo paleoetnobotânico assumia um papel fundamental para a compreensão da jazida e das comunidades que a habitaram. Por acréscimo, não existiam estudos deste tipo no Nordeste português. Os únicos dados carpológicos e paleoeconómicos passíveis de utilizar como paralelo para a realidade estudada são provenientes de escavações de castros da região da Galiza, onde se aponta para a existência de uma importante produção cerealífera, na qual se salientam diversas espécies de trigo, em especial Triticum aestivum, Triticum compactum e Triticum dicoccum. Os milhos (Panicum miliaceum e Setaria italica), a aveia e a cevada seriam cultivos secundários. Entre as leguminosas salienta-se o cultivo de Vicia faba mas também, embora em menor medida, Pisum sativa, Brassica e Sinapis (Ramil-Rego et al., 1996; Rodriguez Lopez, et al. 1993).

Também o consumo humano da bolota encontra-se atestado em diversas jazidas romanas, tanto castros como villae, porém este não seria basilar para a economia e subsistência das comunidades em questão, ao contrário do que sugere Estrabão para tempos pré-romanos (RamilRego, et al., 1996; Rodriguez Lopez, et al., 1993; RamilRego, 1993).

\section{Materiais e métodos}

No Sector B da Terrronha de Pinhovelo, em três campanhas de escavação foram identificadas cinco fases de ocupação. Este estudo irá centrar-se na fase IV, cronologicamente inserida no Baixo-império, na qual se registou um grande esforço de renovação dos espaços domésticos. A sua compreensão só é possível com o devido entendimento da fase anterior:

Fase III: na zona central do Sector foi construído um grande compartimento (Ambiente II), com uma estrutura de combustão constituída por pequenas lajes de xisto cobertas por argila. Na zona Norte foi construído um compartimento (Ambiente $V$ ) e, no seu interior, uma estrutura de armazenagem com o fundo revestido a opus signinum (Ambiente IV) (Figura 2).

Fase IV: foi construído um novo compartimento (Ambiente I) no interior do Compartimento/Ambiente II, parcialmente sobre a referida estrutura de lareira. Neste novo compartimento foram construídas três estruturas de combustão (Figura 2). Os Ambientes I/ e IV continuaram em utilização.

A estratégia de amostragem seguida nas duas campanhas de trabalho foi baseada em princípios definidos na bibliografia (Martínez, et al., 2003; Badal et al.. 2003; Buxo, 1997) ainda que adaptados às condições técnicas disponíveis. Realizaram-se recolhas integrais dos sedimentos das estruturas de combustão espacialmente bem definidas, ao que se aliou a amostragem pontual em estratos com significativa presença de macro-fosseis vegetais. Foram efectuadas também amostragens por estimativa em alguns contextos na fase final dos trabalhos. Paralelamente recolheram-se manualmente os carvões e sementes visíveis nos trabalhos arqueológicos. Todos os sedimentos, com excepção daqueles recolhidos para flutuação, foram crivados a seco.

Na planta da Figura 2 é possível perceber a localização dos principais depósitos (Unidades Estratigráficas - U.E.) amostrados:

-Ambiente l: [65] e [66] representam duas estruturas de combustão. As amostras da U.E. [20] correspondem aos níveis de definição de [65]; e as amostras de [3] correspondem aos níveis de definição de [66].

-Ambiente II: [22] e [71] associam-se a uma estrutura de combustão; [21] e [70] são depósitos dispersos no interior do compartimento e totalmente inseridos neste.

-Ambiente IV: [82] é um derrube no interior desta estrutura de armazenagem, relacionado com o seu momento de abandono, logo, analisado como pertencente à Fase IV.

-Depósito [50]: nos limites exteriores dos Ambientes / e II.

-Depósito [95]: depósito disperso na Zona Este, possivelmente inserido na Fase III.

Após a recolha de amostras no campo foi efectuada uma sub-amostragem em laboratório de forma a tornar exequível o tratamento do grande volume de sedimentos recolhidos. Pretendeu-se que a sub-amostragem garantisse uma caracterização fiável dos contextos em questão.

Os sedimentos foram flutuados nas instalações da Associação Terras Quentes em Macedo de Cavaleiros. Foi utilizado um sistema de "flutuação manual simples" (Buxo, 1997), recorrendo-se a uma coluna de crivos com malhas de $2 \mathrm{~mm}, 1 \mathrm{~mm}, 0,5 \mathrm{~mm}$ e $0,25 \mathrm{~mm}$.

A triagem e observação dos carvões, sementes e frutos foram realizados no Laboratório de Paleoecologia e Arqueobotânica (LPA) do IPA (actual IGESPAR), com a supervisão da Dra. Paula Queiroz. O diagnóstico das sementes e frutos foi realizado à lupa binocular, por comparação com elementos actuais, com recurso à carpoteca em montagem no LPA e a atlas da especialidade (Berggren, 1981; Renfrew, 1973).

No caso específico dos cereais foi seguido o guia de $\mathrm{S}$. Jacomet (2006), complementado com outros estudos (Renfrew, 1973; Buxo, 1997; Murphy, 1989; Van der Veen, 1987). No que respeita à nomenclatura utilizou-se como 


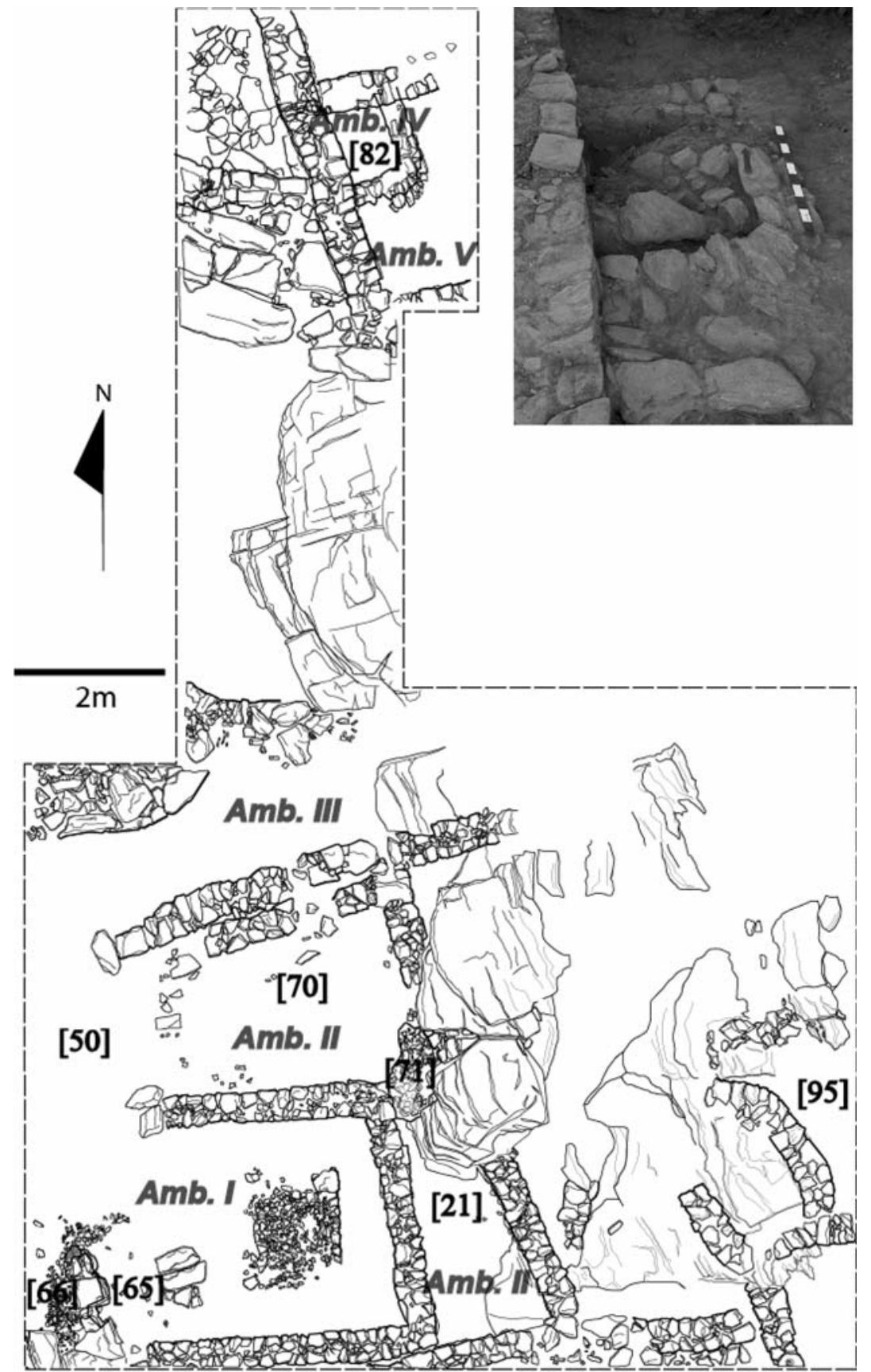

Figura 2.- Planta do Sector $B$ com menção às U.E. amostradas. Acima um pormenor do Ambiente IV referência a proposta de Zohary e Hopf (2000), porém, de forma a tornar prática a nomeação dos tipos morfológicos em texto foram utilizadas abreviaturas:

- Hordeum vulgare - Hordeum vulgare L. subsp. vulgare

-Triticum aestivum, corresponde ao T. aestivum/durum de Buxo (1997) e inclui Triticum aestivum subsp. vulgare (Vill) Mackey, Triticum turgidum conv. durum (Desf.) Mackey e Triticum turgidum conv. turgidum (L.) Mackey.

-Triticum compactum - Triticum aestivum subsp. compactum (Host) Mackey

-Triticum dicoccum - Triticum turgidum L. subsp. dicoccum (Schrank) Thell.
-Triticum monococcum - Triticum monococcum L. subsp. monococcum

-Triticum spelta - Triticum aestivum subsp. spelta (L.) Thell.

\section{Resultados}

Os cereais são o cultivo mais representado no estudo carpológico, tendo sido recolhidas cariopses e espiguetas de várias espécies, em especial de trigo e cevada (Quadro 1). Tendo em conta a sub-amostragem realizada, foi efectuado um cálculo para perceber a potencial quantidade de cariopses existente em cada amostra (Quadro 2). 


\begin{tabular}{|c|c|c|c|c|c|c|c|c|c|c|c|c|}
\hline & \multicolumn{4}{|c|}{ Ambiente I } & \multicolumn{4}{|c|}{ Ambiente II } & \multirow{2}{*}{\begin{tabular}{|l|} 
A.IV \\
{$[82]$} \\
\end{tabular}} & \multirow[b]{2}{*}[50]{} & \multirow[b]{2}{*}{ [95] } & \multirow[b]{2}{*}{ TOTAL } \\
\hline & [3] & {$[66]$} & {$[20]$} & {$[65]$} & [21] & [70] & [22] & {$[71]$} & & & & \\
\hline T. monococcum & & 1 & & & & & 2 & & & & & 3 \\
\hline T. dicoccum & 28 & 25 & 17 & 31 & 8 & 8 & & 2 & & & 2 & 121 \\
\hline T. cf. dicoccum & 1 & 2 & & 6 & & & & 1 & & & & 10 \\
\hline T. dicoccum/aestivum & 1 & 6 & & 4 & & & & & 1 & 1 & & 13 \\
\hline T. dicoccum/spelta & 1 & 4 & & & 1 & & & & & & & 6 \\
\hline T. spelta & 1 & 4 & 2 & 4 & & 3 & & 1 & & & 1 & 16 \\
\hline T. cf. spelta & & & & 1 & & & & & & & & 1 \\
\hline T. aestivum & 24 & 20 & 10 & 24 & 1 & 7 & 1 & 1 & & & & 88 \\
\hline T. cf. aestivum & 1 & 3 & 1 & 1 & & 1 & & & & & & 7 \\
\hline T. aestivum/compactum & & & & 2 & & & & & & & & 2 \\
\hline T. compactum & 14 & 10 & 6 & 16 & 8 & 6 & & 1 & & & 1 & 62 \\
\hline T. cf. compactum & & 1 & & 1 & & & & & & & & 2 \\
\hline Triticum sp. & 57 & 55 & 14 & 21 & 2 & 15 & & 4 & 2 & 4 & 5 & 179 \\
\hline H. vulgare & 14 & 8 & 19 & 44 & 22 & 26 & 3 & 4 & 2 & 4 & 2 & 148 \\
\hline Hordeum sp. & & 1 & & & 1 & & & & & 2 & 2 & 6 \\
\hline Indeterminado & & 1 & & 2 & & & & & & & & 3 \\
\hline TOTAL & 142 & 141 & 69 & 157 & 43 & 66 & 6 & 14 & 5 & 11 & 13 & 667 \\
\hline
\end{tabular}

\begin{tabular}{|c|c|c|c|c|c|c|c|c|c|c|c|c|}
\hline & \multicolumn{4}{|c|}{ Ambiente I } & \multicolumn{4}{|c|}{ Ambiente II } & \multirow{2}{*}{\begin{tabular}{|l|}
$A . I V$ \\
{$[82]$} \\
\end{tabular}} & \multirow[b]{2}{*}{ [50] } & \multirow[b]{2}{*}{ [95] } & \multirow[b]{2}{*}{ TOTAL } \\
\hline & {$[3]$} & [66] & [20] & [65] & [21] & [70] & [22] & [71] & & & & \\
\hline T. monococcum & & 11 & & & & & 8 & & & & & 19 \\
\hline T. dicoccum & 185 & 276 & 46 & 218 & 22 & 30 & & 5 & & & 9 & 792 \\
\hline T. cf. dicoccum & 7 & 22 & & 42 & & & & 2 & & & & 73 \\
\hline T. dicoccum/aestivum & 7 & 66 & & 28 & & & & & 3 & 6 & & 110 \\
\hline T. dicoccum/spelta & 7 & 44 & & & 3 & & & & & & & 54 \\
\hline T. spelta & 7 & 44 & 5 & 28 & & 11 & & 2 & & & 5 & 103 \\
\hline T. cf. spelta & & & & 7 & & & & & & & & 7 \\
\hline T. aestivum & 159 & 221 & \begin{tabular}{|l|}
27 \\
\end{tabular} & 169 & 3 & 26 & 4 & 2 & & & & 612 \\
\hline T. cf. aestivum & 7 & 33 & 3 & 7 & & 4 & & & & & & 53 \\
\hline T. aestivum/compactum & & & & 14 & & & & & & & & 14 \\
\hline T. compactum & 93 & 110 & 16 & 113 & 22 & 23 & & 2 & & & 5 & 384 \\
\hline T. cf. compactum & & 11 & & 7 & & & & & & & & 18 \\
\hline Triticum sp. & 378 & 608 & 38 & 148 & 5 & 56 & & 10 & 7 & 24 & 23 & 1298 \\
\hline H. vulgare & 93 & 88 & 52 & 310 & 60 & 98 & 12 & 10 & 7 & 24 & 9 & 763 \\
\hline Hordeum sp. & & 11 & & & 3 & & & & & 12 & 9 & 35 \\
\hline Indeterminado & & 11 & & 14 & & & & & & & & 25 \\
\hline TOTAL & 941 & 1558 & 188 & 1106 & 117 & 248 & 24 & 35 & 17 & 67 & 61 & 4361 \\
\hline
\end{tabular}

Quadro 1.- Cariopses de trigo e cevada identificadas nas sub-amostras

\section{Trigos}

É evidente pela leitura dos quadros 1 e 2 que as cariopses de cereais existem em maior quantidade nas estruturas de combustão e depósitos que Ihes estão associados, em especial do Ambiente I. Por outro lado, não existe uma diferença significativa entre a quantidade de trigos de semente vestida e os de semente nua, embora se denote um ligeiro domínio dos segundos.

Entre as cariopses de trigo vestido salienta-se o morfotipo Triticum. aestivum/durum apesar de se contar com uma presença muito significativa de $T$. compactum. Já no que respeita aos trigos de grão vestido, o tipo morfológico mais abundante é $T$. dicoccum enquanto que T. monococcum é mesmo residual. Contudo, deve-se salientar as grandes dificuldades existentes no que respeita à distinção dos grãos de T. dicoccum e T. spelta. S. Jacomet (2006) sugere mesmo não ser possível distinguir as duas espécies quando os grãos de $T$. spelta são carbonizados ainda na espigueta. Este facto é bastante relevante tendo em conta que a quantidade de fragmentos de espiguetas recolhidos, assim como a detecção de grãos ainda no interior das respectivas espiguetas sugere que muitas cariopses terão sido submetidas ao fogo antes da descorticação.

A leitura dos dados referentes aos fragmentos de espiguetas fornece uma perspectiva distinta da das cariopses (Quadro 3). De facto, os fragmentos de glumas e bases de espiguetas classificados como $T$. spelta são bastante mais abundantes que os de $T$. dicoccum, em especial nos contextos mais circunscritos, as áreas de combustão [65] e [66] e os depósitos [20] e [3] que lhes estão associados.

Considera-se, assim, que os dados das cariopses conduziram a uma sobrevalorização da presença de $T$. dicoccum, quando, na verdade, T. spelta seria o trigo vestido mais abundante das amostras estudadas da Terronha de Pinhovelo. Refira-se que foi descrita uma situação semelhante no estudo carpológico da jazida de Cortaillod/Sur les Rochettes-est, na Suiça, onde foi estudada uma maior quantidade de macro-restos, tendo o autor chegado às mesmas conclusões (Akeret, 2005). 


\begin{tabular}{|c|c|c|c|c|c|c|c|c|c|c|c|}
\hline & \multicolumn{4}{|c|}{ Ambiente I } & \multicolumn{3}{|c|}{ Ambiente II } & \multirow[b]{2}{*}{ [50] } & \multirow[b]{2}{*}{ [95] } & \multirow[b]{2}{*}{ TOTAL } \\
\hline & & [3] & [66] & [20] & [65] & [21] & [70] & [71] & & & \\
\hline T. monococcum & Espigueta & & 2 & & 1 & & & & & & 3 \\
\hline \multirow{2}{*}{ T. dicoccum } & Bases de gluma & 2 & 2 & & 1 & 2 & 1 & & 1 & & 9 \\
\hline & Espigueta & & & & 2 & & & & & & 2 \\
\hline \multirow{2}{*}{ T. spelta } & Bases de gluma & 12 & 18 & 8 & 13 & 4 & 4 & 1 & 1 & 2 & 63 \\
\hline & Espigueta & 1 & 6 & 4 & 3 & & & & 1 & & 15 \\
\hline
\end{tabular}

Quadro 3.- Partes de espiguetas identificadas nas sub-amostras (e por isso só comparável com os dados de cariopses do Quadro 1)

\section{Cevada}

No que respeita à cevada, a totalidade das cariopses identificadas pertencem à variante de grão vestido. Embora não seja tão abundante quanto o trigo, a verdade é que não se pode considerar a sua presença minoritária tendo em conta que, entendendo cada morfotipo em separado, a cevada é mais abundante que a maioria dos trigos, só sendo suplantada por T. dicoccum.

Surge como espécie de cereal dominante no Ambiente II, nomeadamente nos depósitos [21] e [70], onde apresenta maiores índices de concentração (semente por $\mathrm{Kg}$ de sedimento) do que nas estruturas de combustão do Ambiente I.
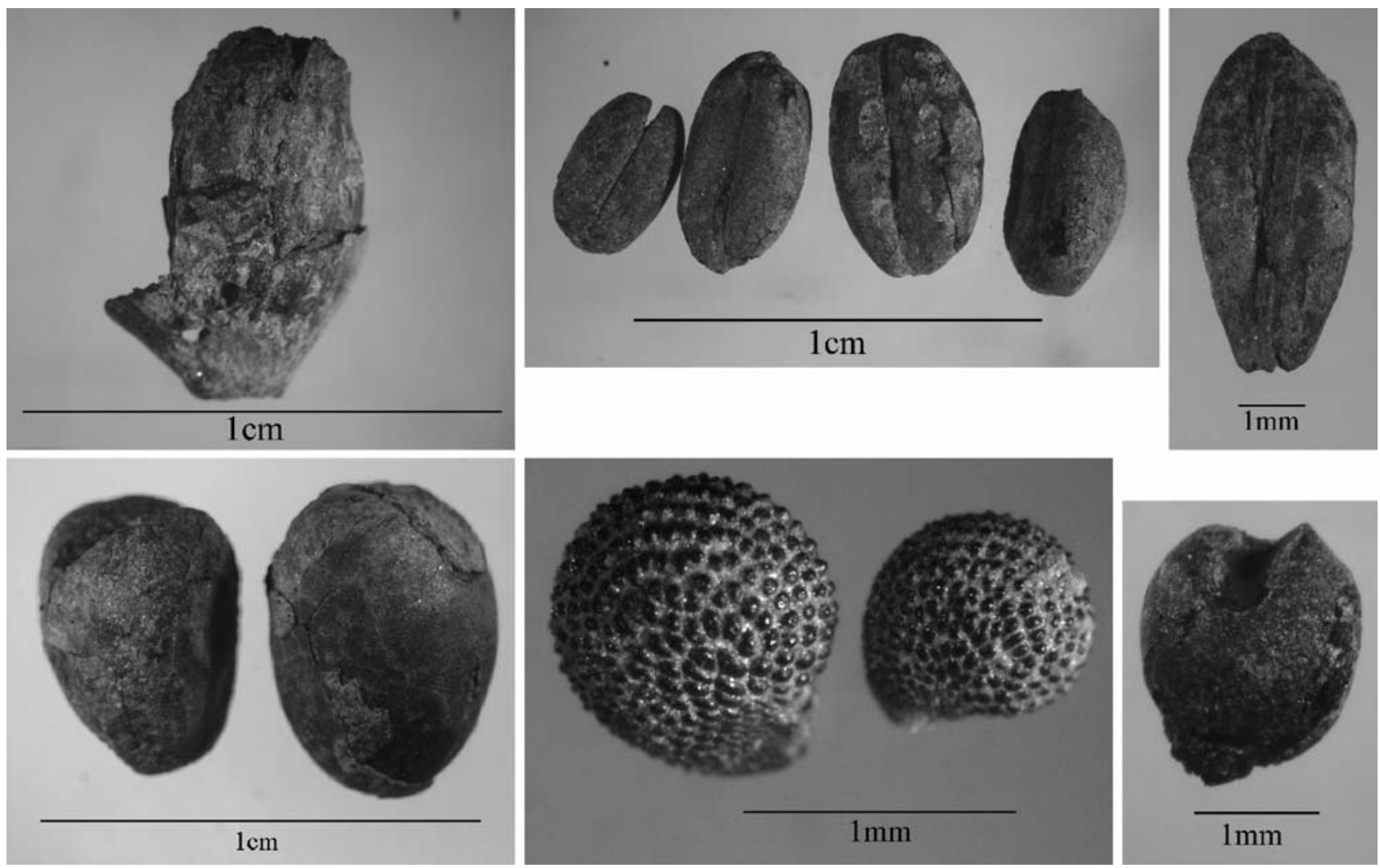

Figura 3.- Espigueta e grão de T. spelta; T. aestivum; Hordeum vulgare; Vicia faba minor; Portulaca oleraceae; Panicum miliaceum

Milho

Foram recuperadas algumas cariopses de milho nos contextos arqueológicos da Terronha de Pinhovelo. Enquanto que somente um grão foi identificado como Setaria italica, treze foram classificados como Panicum miliaceum. Estes são, contudo, sempre minoritários nas sub-amostras face às outras espécies de cereal.

Somente no interior da estrutura de armazenagem, na U.E.
[82], o milho se encontra em quantidades semelhantes às dos restantes cereais (2 grãos), mas a diminuta quantidade de sementes aí recolhida não permite qualquer conclusão mais arrojada.

De resto, todas as áreas de combustão dos compartimentos em questão forneceram grãos de milho, mas em percentagens muito pequenas face aos restantes cereais (4\%). No cômputo geral das amostras o milho completa somente $2 \%$ do total dos cereais encontrados. 


\begin{tabular}{|c|c|c|c|c|c|c|c|c|c|c|}
\hline & \multicolumn{4}{|c|}{ Ambiente I } & \multicolumn{4}{|c|}{ Ambiente II } & \multirow{2}{*}{$\begin{array}{l}. I V \\
82 \\
\end{array}$} & \\
\hline & [3] & {$[66]$} & {$[20]$} & {$[65]$} & [21] & [70] & {$[22]$} & {$[71]$} & & {$[95$} \\
\hline Vicia faba var. minor & 1 & & 8 & 47 & 2 & 1 & & & & 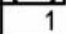 \\
\hline Setaria italica & & 1 & & & & & & & & \\
\hline Panicum miliaceum & & 1 & & 1 & 1 & 2 & 1 & 2 & 2 & \\
\hline
\end{tabular}

Quadro 4.- Quantidade de favas e milho nas subamostras

\section{Leguminosae}

As sementes de leguminosas identificadas no estudo carpológico pertencem todas a Vicia faba var. minor. Embora ocorram em quantidades significativas, as favas não se encontram homogeneamente distribuídas pelas subamostras e pela área de escavação. De facto, das 60 sementes recolhidas por flutuação, 47 foram encontradas na área de combustão [65] e outras 8 são provenientes do depósito que the está associado, a U.E. [20]. Ou seja, $91,7 \%$ do total de favas pertencem a um mesmo contexto, uma estrutura de combustão do Ambiente I. Deve-se ainda referir que tendo em conta que só foi sub-amostrado $14,2 \%$ do sedimento da U.E. [65], esta contaria, potencialmente, com um total de 331 favas, sendo assim mais abundante do que qualquer morfotipo de cereal, embora no seu todo o trigo seja mais frequente.

\section{Outras especies}

Foram encontrados poucos indícios de espécies silvestres nos contextos estudados. Como é possível ver no quadro 5 , várias espécies silvestres só se encontram representadas num contexto e, ainda assim, em pequenas quantidades. A U.E. [70] foi o contexto que mais espécies silvestres forneceu, seguido de [3].

Os tipos morfológicos mais comuns e representados num maior número de U.E. são Portulaca oleracea e cf. Lolium. Embora as beldroegas (Portulaca oleracea) sejam mais frequentes em contextos ruderais e hortícolas, Polygonum aviculare e Lolium sp. poderão resultar de contaminações durante a colheita cerealífera, visto ocorrerem frequentemente como infestantes desses contextos. A inexistência de qualquer gramínea selvagem em [65] é mais um factor de distinção entre esta área de combustão e a [66].

\begin{tabular}{l|c|c|c|c|c|c|c|c|c|c|c}
\cline { 2 - 14 } & \multicolumn{9}{c}{ Ambiente } & \multicolumn{3}{c|}{ Ambiente II } & A. IV & \multicolumn{2}{l}{} \\
\hline & {$[3]$} & {$[66]$} & {$[20]$} & {$[65]$} & {$[21]$} & {$[70]$} & {$[22]$} & {$[71]$} & {$[82]$} & {$[50]$} & {$[95]$} \\
\hline Anthemis cotula & 1 & & & & & & & & & & \\
\hline cf. Aquilegia sp. & 1 & & & & & & & & & & \\
\hline Brassica sp. & 1 & & & & & & & & & & \\
\hline cf. Cerastium sp. & & & & & 1 & & & & & & \\
\hline Cistus sp. & & & & & & 1 & & & & & \\
\hline Erica scoparia - folhas & & & & & & 3 & & & & & \\
\hline Erica sp. folhas & & & & & & 2 & & & & & \\
\hline Euphorbia helioscopia tipo & & & & & & & & & 1 & & \\
\hline Graminea - indeterminado & & & & & & 3 & & & & & \\
\hline cf. Lolium & 1 & 4 & 1 & & 1 & 1 & & & 1 & 1 & \\
\hline cf. Lolium - frag & & 4 & 2 & & & & & & & & 1 \\
\hline Polygonum aviculare & & 1 & & 2 & & 1 & & & & & \\
\hline Polygonum bifacetado & & & 1 & & & & & & & & \\
\hline Portulaca oleraceae & 8 & 3 & 6 & 4 & & 1 & & & & & \\
\hline Quercus sp. - frag & & & & & 5 & & 1 & 1 & & & \\
\hline Rumex crispus tipo & & & & & & & & & & & 1 \\
\hline Sambucus cf. ebulus & & & & & & & & & 1 & & \\
\hline Fruto indeterminado & & & & & 1 & & & & & & \\
\hline Indeterminado & 1 & & & & 1 & 1 & & & 1 & & \\
\hline Indeterminado - frag. & 1 & & & & & 1 & 5 & 4 & & & \\
\hline
\end{tabular}

Quadro 5.- Espécies silvestres detectadas na Terronha de Pinhovelo
A presença de uma semente de Brassica sp., poderá sugerir o seu cultivo. Contudo, não se exclui a possibilidade de pertencer a uma espécie silvestre deste género.

Por fim, deve-se fazer uma referência à presença de glandes de bolota. Os contextos onde foram recolhidos ([21], [22] e [71]) encontram-se associados à estrutura de combustão do Ambiente II. Em [22] foram recolhidos manualmente 34 fragmentos de glande de bolota.

\section{Distribuição pelos diferentes contextos}

Como foi já indiciado, as diferentes espécies não apresentam uma distribuição homogénea pelos diferentes contextos estruturais e sedimentares identificados e amostrados.

No Ambiente I, foram amostradas duas estruturas de combustão. Na U.E. [65] a espécie mais abundante é a Vicia faba var. minor. Entre os cereais, a cevada é a espécie 
mais abundante, seguida de T. spelta/dicoccum. Os trigos nus, T.aestivum/durum e T. compactum são também frequentes. Panicum miliaceum é residual.

$\mathrm{Na}$ U.E. [66], não se encontra qualquer unidade de fava (contam-se residuais fragmentos de pequenas dimensões, sem hilo) e a cevada é o cereal menos frequente. $T$. spelta/dicoccum e $T$. aestivum/durum são particularmente abundantes, embora também $T$. compactum seja frequente. T. monococcum, ao contrário da estrutura anterior, surge neste contexto, ainda que em pequenas quantidades. $O$ mesmo acontece com Panicum miliaceum, Setaria italica (a única cariopse desta espécie surge aqui) e cf. Lolium sp. Nesta estrutura salienta-se, porém, a grande quantidade de cariopses de trigo em mau estado de conservação e que, por isso, não se logrou uma identificação além do género.

No Ambiente II, foi escavada uma estrutura de combustão e dois depósitos da última fase de ocupação. A estrutura [71], dado o seu pequeno volume sedimentar, apresenta poucas cariopses, sendo mais abundantes a cevada e Triticum sp. Apresenta ainda milho-miúdo e um fragmento de glande de bolota. Contudo as bolotas são mais abundantes no depósito [22], associado a esta mesma estrutura.

Nos depósitos que preenchem este compartimento (Ambiente II) as bolotas também estão presentes. A cevada é claramente o cereal mais abundante, embora também se identifiquem os diferentes morfotipos de trigo. De resto são os contextos com maior diversidade de espécies silvestres.

Nos restantes contextos amostrados a quantidade de vestígios carpológicos não é muito significativa. O resultado mais decepcionante é mesmo o da U.E. [82], que preenchia uma estrutura de armazenagem. São aí escassos os cereais, contando-se ainda poucas sementes de silvestres. A presença de cereais em [50] poderá ser justificada pela sua proximidade com os Ambientes I e II, enquanto que a presença em [95] só poderá ser compreendida verdadeiramente com o alargamento da área de escavação e a continuação da intervenção nesse contexto.

\section{Discussão e conclusão}

Paradoxalmente, ainda que as práticas de monocultura se tenham generalizado na época romana e assumido um importante papel para impulsionar a economia agrícola, vários estudos apontam que uma das principais inovações da agricultura romana foi a diversificação de cultivos (Buxo, 2005; Prevosti e Guitart, 2005). Contudo, nas amostras da Terronha de Pinhovelo até agora estudadas as únicas culturas das quais restaram vestígios carpológicos foram os cereais e as favas. Entre os cereais destacam-se Triticum aestivum/durum, T. spelta/dicoccum, T. compactum, e Hordeum vulgare. Em menores quantidades detectaram-se T. monococcum, Panicum miliaceum e Setaria italica.

Há que salientar que, sendo evidente a presença e importância do trigo, faltam dois elementos da tríade mediterrânica característica do mundo romano e identificada noutras regiões peninsulares (Prevosti e Guitart, 2005): a vinha e a oliveira. Apesar da especificidade dos contextos da Terronha de Pinhovelo aqui estudados poderem ter um papel importante nestes dados, é evidente nos estudos carpológicos do NW peninsular que estes dois elementos não são particularmente abundantes nesta área geográfica (Ramil-Rego et al., 1996), o que poderá testemunhar não só diferenças culturais significativas como também diferentes níveis de romanização e integração no império.

O cultivo conjunto de distintas espécies nos mesmos terrenos poderia ser uma prática comum, tal como aparece atestada em tempos mais recentes. Os diversos trigos vestidos podem ser plantados e até colhidos em conjunto pois os processos que se seguem à segada são semelhantes para todos (Peña-Chocarro, 1999). Seguindo esta linha de raciocínio, poderemos pressupor que as variedades vestidas e nuas de trigo seriam cultivadas em separado. Acrescente-se ainda que, segundo Marinval (1992), as duas espécies de milho poderiam ser cultivadas juntas.

A presença das diferentes espécies de cereais e da fava poderá sugerir, ainda que de forma especulativa, a existência de uma alternância de cultivos. Buxo e colaboradores (1995) colocam a possibilidade de ter existido em épocas proto-históricas, na Catalunha, um sistema de cultivo trienal, à base de trigo, cevada e leguminosas, que permitia manter a fertilidade dos solos. A verificar-se uma situação semelhante em época romana na região da Terronha de Pinhovelo, a leguminosa que participaria nesta rotatividade deveria ser a fava.

De resto, a alternância entre cereais e outras espécies como estratégia de cultivo não constitui um comportamento estranho na região em tempos mais recentes (Taborda, 1932).

A recolha de cariopses de milho, apesar de minoritárias no conjunto carpológico, é um aspecto importante para a compreensão das estratégias agrícolas das populações que habitaram esta povoação durante o século IV. A importância da presença dos milhos reside no facto de, enquanto cereais de Primavera, o seu cultivo permitir compensar as más colheitas de Inverno (de trigo). Esta complementaridade entre cultivos é essencial para as comunidades camponesas e pressupõe a existência de uma grande variabilidade de espécies cultivadas (Fernandez-Posse e Sánchez-Palencia, 1998).

Por fim, devem ser feitas algumas observações acerca da presença de sementes de Portulaca oleracea. Sendo a horta um espaço muito importante no território rural, não se deve excluir a possibilidade de ter existido uma gestão hortícola da beldroega, espécie ruderal da qual existem variedades cultivadas. Note-se porém que a beldroega consiste numa planta nitrófila que cresce espontânea e abundantemente nos espaços ruderalizados, pelo que, o seu consumo pela comunidade não implica o seu cultivo, podendo a sua presença resultar apenas de práticas de recolecção ou mesmo contaminação de outras culturas. As mesmas considerações poderão ser feitas acerca das espécies de Polygonum encontradas.

De resto, o registo antracológico forneceu evidências da existência na paisagem de outras espécies que poderão ter 
sido alvo de uma exploração para fins alimentares, nomeadamente Arbutus unedo, Corylus avellana, Prunus spinosa e Sorbus sp. (Tereso, 2007). Contudo, os vestígios detectados (a madeira carbonizada) não permitem certificar a recolha dos seus frutos. Seria ingénuo pensar que não existia uma exploração desses recursos em época romana. É, no entanto, impossível saber se essa exploração implicou uma gestão efectiva das comunidades vegetais existentes na paisagem ou se se realizaram meras práticas de recolecção.

Na região do Noroeste Peninsular usualmente aponta-se a existência de um domínio, entre as espécies de cereais, de Triticum aestivum e $T$. compactum entre os cereais hexaploides e de Triticum dicoccum entre os tetraploides (Ramil-Rego et al., 1996; Rodriguez Lopez, et al., 1993). Na Terronha de Pinhovelo, as cariopses destes tipos morfológicos também são as mais frequentes, porém, no caso de $T$. dicoccum, existem maiores cautelas na interpretação dos dados biométricos e morfológicos que sustentam a sua distinção face a $T$. spelta. Este último encontra-se pouco documentado na região, apesar de poder encontrar-se erroneamente sub-representado face a T. dicoccum.

Os milhos e a cevada são tidos como cultivos secundários na região. Embora tal se confirme, na Terronha de Pinhovelo, para o milho-míudo, a cevada parece ter tido um papel importante. Não obstante, estando os trabalhos de escavação ainda pouco desenvolvidos, não se exclui a possibilidade de a especificidade dos contextos estudados poder condicionar esta leitura geral.

O cultivo de favas também está documentado para a região, sendo mesmo a leguminosa mais representativa (RamilRego et al., 1996) pelo que a sua presença na Terronha de Pinhovelo encontra-se enquadrada cultural e cronologicamente.

De igual modo é conhecido o papel das bolotas na alimentação humana das comunidades proto-históricas NW peninsular, não como fonte alimentar primordial mas sim secundária e complementar de práticas agro-pastoris. A sua presença aqui, bem como em outras jazidas romanas, deve ser considerada normal, após a desmistificação do eventual atraso tecnológico e cultural que anteriormente se atribuía ao seu uso para fins alimentares. A identificação das bolotas entre os carporestos da Terronha de Pinhovelo, pela sua relativa escassez, não pode ser utilizada como uma evidência clara de práticas silvícolas sendo natural que resulte apenas de práticas de recolecção.

Por fim, é possível afirmar que na fase actual dos trabalhos da Terronha de Pinhovelo não se dispõe de uma superfície de escavação suficientemente grande (proporcionalmente à dimensão da jazida e face ao tipo e cronologia do povoado) para conseguir uma amostragem notável. Só o enriquecimento deste estudo durante as próximas campanhas arqueológicas poderá suprir a escassez de dados.

Agradecimentos Agradeço à Dra. Paula Queiroz e ao Prof. Dr. José Pissarra a orientação na tese que serviu de base a este estudo. Um agradecimento também a toda a equipa da
Associação Terras Quentes, onde estive inserido durante parte deste estudo; à Cristiana Vieira pela ajuda no tratamento estatístico dos dados; à Helena Barranhão e à Lúcia Miguel com quem formei uma equipa no trabalho de campo. À Rita Gaspar.

\section{Bibliografia}

Badal, E.; Carrión, Y.; Rivera, D.; Uzquiano, P. (2003). La Arqueobotânica en cuevas y abrigos: objectivos y métodos de muestreo. In Buxó, R. e Piqué, R. (dir.), La recogida de muestras en arqueobotánica: objectivos y propuestas metodológicas. La gestión de los recursos vegetales y la transformación del paleopaisaje en el Mediterráneo occidental. Museo d'Arqueologia de Catalunya. Barcelona. 19-29.

Barranhão, H.; Tereso, J. (2006). (2006). A Terronha de Pinhovelo na ciuitas zoelarum: primeira síntese. Cadernos “Terras Quentes", 3: 7-26.

Berggren, G. (1981). Atlas of seeds and small fruits of Northwest-European plant species with morphological descriptions. Vol. 3. Salicaceae-Cruciferae. Swedish Museum of Natural History.

Buxó, R. (1997). Arqueologia de las plantas. Crítica. Barcelona.

Buxó, R. (2005). L'agricultura d'època romana: estudis arqueobotànics $\mathrm{i}$ evolució dels cultius a Catalunya. Cota Zero, 20: 108-120.

Buxó, R.; Alonso, N.; Canal, D.; Català, M.; Echave, C.; González, I. (1995). Estudios recientes sobre agricultura y alimentación vegetal a partir de semillas y frutos en Catalunya (Neolítico-2 ${ }^{a}$ Edad del Hierro). Actas do $1^{\circ}$ Congresso de Arqueología Peninsular. Trabalhos de Antropología e Etnologia. 35, 1: 467-483.

Fernández-Posse, M.; Sánchez-Palencia, F. (1998). Las comunidades campesinas en la cultura castreña. Trabajos de Prehistoria. 55, 2: 127-150.

Guerra, A. (1995). Plínio-o-Velho e a Lusitânia. Faculdade de Letras da Universidade de Lisboa/Edições Colibri. Lisboa.

Jacomet, S. (2006). Identification of cereal remains from archaeological sites. $2^{\text {nd }}$ edition.

Consultado

em:

http://pages.unibas.ch/arch/archbot/pdf/index.html

Marinval, P. (1992). Archaeobotanical data on millets (Panicum miliaceum and Setaria italica) in France. Review of Palaeobotany and Palynology. 73: 259-270. 
Martinez, N.; Juan-Tresserras, J.; Rodríguez-Ariza, M.; Buendia, N. (2003). Muestreo arqueobotánico de yacimientos al aire libre y en medio seco. In Buxó, R. e Piqué, R. (dir.), La recogida de muestras en arqueobotánica: objectivos y propuestas metodológicas. La gestión de los recursos vegetales y la transformación del paleopaisaje en el Mediterráneo occidental. Museo d'Arqueologia de Catalunya. Barcelona. 31-48.

Murphy, P. (1989). Carbonised neolithic plant remains from the Stumble, an intertidal site in the Blackwater Estuary, Essex, England. Circaea. 6, 1: 21-38.

Pena-Chocarro, L. (1999). Prehistoric Agriculture in Southern Spain during the Neolithic and the Bronze Age. The application of ethnographic models. BAR International Series.

Prevosti I Monclus, M.; Guitart I Duran, J. (2005). Els estudis del món agrari romà a Catalunya: un estat de la quesito. Cota Zero. 20: 41-52.

Ramil-Rego, P. (1993). Paleoethnobotánica de yacimientos arqueológicos holocenos de Galicia (N.O. Cantábrico). Munibe. 45: 165-174.

Ramil-Rego, P.; Dopazo Martinez, A.; Fernández Rodriguez, C. (1996). Cambios en las estrategias de explotación de los recursos vegetales en el Norte de la Península Ibérica. Férvedes. 3: 169-187.
Renfrew, J. (1973). Palaeoethnobotany. The prehistoric food plants of the Near East and Europe. Columbia University Press. New York.

Rodríguez Lopez, C.; Fernandez Rodriguez, C.; RamilRego, P. (1993). El aprovechamiento del Medio Natural en la cultura castreña del Noroeste Peninsular. Trabalhos de Antropología e Etnologia. 33, 1-2: 285-305.

Silva, A. (2007). A Terra Sigillata Hispânica Tardia de Terronha de Pinhovelo: o comércio e o povoamento. Cadernos Terras Quentes, 4: 6-50.

Taborda, V. (1932). Alto Trás-os-Montes. Estudo Geográfico. Imprensa da Universidade. Coimbra.

Tereso, J. (2007). Paleoetnobotânica do povoado romano da Terronha de Pinhovelo (NE transmontano). Dissertação de mestrado apresentada à Faculdade de Ciências da Universidade do Porto.

Van Der Veen, M (1987). The plant remains. In Heslop, D., The Excavation of an Iron Age Settlement at Thorpe Thewles, Cleveland, 1980-1982. (CBA Research Report, 65). London. 93-99.

Zohary, D.; Hopf, M. (2000). Domestication of Plants in the Old World. The origin and spread of cultivated plants in West Asia, Europe and the Nile Valley. $3^{\text {rd }}$ Edition. Oxford University Press. 